system, and tentacles-underwent a marked decrease ; so that at last I was only able to obtain specimens one half or one quarter the ordinary size of Aurelia aurita, and having nearly all their natural rose-pink colour discharged. I believe that these two phenomena-the loss of colour and the diminution in size-are related to one another in a very intimate manner. Just at the time of year when these two phenomena began to inanifest themselves, I observed that all the specimens of Aurelia I met with were infested by a species of crustacean, which lodged chiefly in the ovaries and nutritive canals. These crustaceans appeared to devour with avidity all the coloured parts of their hosts, and I think it was probably due to the ever-increasing numbers of these parasites that the size of the individuals composing the incoming generations of Aurelic continued to become more and more diminutive. $\Upsilon$ shall, however, attend to all these points more closely next year, after which I shall doubtless be able to speak with more certainty regarding them.

\section{SCIENTIFIC SERIALS}

American Fournal of Science and Arts, March. - In this number $\mathrm{Mr}$. Trouvelot directs attention to the phenomenon of what he calls "veiled solar spots." During last year, the chromosphere has been notably thinner than usual, and the granulations smaller and less numerous, rendering more conspicuous the light-grey coloured back-ground between the granules. The veiled spots are seen through the chromosphere that is spread over them like a veil; they are, like ordinary spots, true openings of the photosphere ; they are scattered throughout all latitudes, though more complicated in regions where the ordinary spots make their appearance. Mr. Trouvelot has observed spots at least within Io degrees of the north pole of the sun (very few of the ordinary spots have hitherto been observed beyond 40).Prof. Kimball describes an ingenious arrangement by which he demonstrates that the law affirming the coefficient of friction on an inclined plane to be constant for all velocities, is not strictly true. The sliding box had a cover 6 feet long, wilh strips of smoked glass upon it, on which a tuning fork, fixed above to an independent support, traced a wave-line as the box slid down, thus giving a perfect autographic register of the experiment.-A new method of measuring the velocity of electricity is described by $\mathrm{P}_{i}$ of. Lovering. He avails timself of Lissajous' method of compounding the rectangular vibrations of two tuning forks, the reflected beam entering a telescope. The forks being maintained in vibration by electro-magnets and brought into unison, the resultant orbit seen in the telescope is invariable. A length of resistance coil is introduced sufficient to change the orbit to some other in the series, and this change reveals the amount of retardation of the one fork's vibrations, due to the inserted resistance. -Prof. Mallet discusses the constitutional formulæ of urea, uric acid, and their derivatives. - A new trilobite, Dalmanitis dentata is described by Dr. Barrett, and Prof. Marsh gives (in an appendix) the principal characters of Tillodontia, a new order of extinct mammals found in the Eocene deposits of North A merica.-Mr. Wallace gives an account of some flint implements found in the stratified drift in the vicinity of Richmond, Virginia, and there are one or two notes on points in American geology.

Pogoendorf's Annalen der Physik und Chemie, No. 12, 1875. - A few years ago, separate researches were published by N arr and Stefan, on the conduction of heat in gases. M. Winkel. mann here extends the inquiry, his object having been to ascertain how far production of currents and radiation affected the velocity of cooling, to study the behaviour of more gases, in order to a fuller comparison with theory, and to determine the dependence of heat-conduction of gases on temperature (the last is reserved for another paper). His apparatus was substantially like Stefan's, and he examined ten gases. The numbers obtained differ considerably from those of Narr, in whose experiments, he thinks, currents had not been avoided, and had contributed not a Jittle to the velocity of cooling. Stefan's value for air is 6 per cent. greater than the author's, and this difference is explained by radiation, which Stefan had not taken into account.-M. Weber studies the coloured products obtained through the action of sulphur and selenium on sulphuric acid anbydride. He has got from this action a new oxygen compound of sulphur and a corresponding substitution product of selenium. The former contains twice as much sulphur as sulphuric acid $\left(57^{\circ} \mathrm{I}_{4}\right.$ per cent.), and the formula assigned is $\mathrm{S}_{2} \mathrm{O}_{3}$. M. Weber proposes for it the name of sesquioxide of sulphur, or dithionoxide. In the dry state it forms bluish-green crystals, and is like malachite in structure.
Liquid only in the moment of production, it soon solidifies and cannot be fused again without decomposition. In a cool chamber, decomposition occurs but slowly. The selenium compound is denoted by the formula $\mathrm{Se} \mathrm{SO}_{3}$ (it requires 49.68 per cent. selenium, $20 \cdot 12$ per cent. sulphur.) The crystallised solid is of a dirty green colour, and it is much more stable than dithionoxide.-Before his death, Prof. J. J. Müller was engaged in experimenting on the influence of insulators on induction; and he communicated to Dr. Fiedler the following results. (I) Insulating media exercise, on the strength of induction, the opposite influence to the induced magnetism of the conductors. (2) Static electricity accumulated on insulators, exerts an influence on the strength of induction. Dr. Kleiner here gives details of the experiments, from which these conclusions were formed. - In a paper on thermo-electricity, M. Kohlrausch considers that for a theory of the phenomena, we do not need an immediate action of the contact surfaces, but can arrive at full agreement with the facts by assuming electromotive forces in the interior of the conductors, the places of contact having only a secondary influence. In every thermopile, when in action, there necessarily is $s_{j}$ with the difference of temperature, a streaming over of heat from the hotter to the colder junction. The difference of temperature of the soldered parts has hitherto been thought the cause of the electromotive force; but with equal right we may take as basis the other inseparable circumstance, and suppose that with a heat current in a determinate mass, dependent on the nature of the conductor, an electric current is connected (provided that other electromotive forces are first excluded). These ideas are deve loped in the paper. - M. Holt $z$ communicates the results of various attempts to improve the simple "influence" machines; and Prof. Lommel furnishes an elementary treatment of some optical problems, the smallest deflection in the prism, the achromatic prism, and the elementary theory of the rainbow.-M. Edlund deals with two objections to his unitarian theory of electricity ; one by Prof. Newman, that to explain unipolar induction, the presence of at least two electric fluids is necessary; the other by $M$. Baumgartner, that the unitarian theory seems to contradict the supposition that vacant space has no conductivity for the galvanic current.-M. Sadebeck contributes some mineralogical studies from Kiel University; and among other subjects treated in this number are, the behaviour of electricity in electrolytes (Budde) and the alteration of the velocity of light in quartz through pressure (Mach and Merten).

Memorie Della Societa degli Spettroscopisti Italiani, Sept. 1875. - Prof. Tacchini continues his detailed remarks on sun-spois and faculæe observed by him at Palermo in 1873 . The spectral lines of the prominences in the neighbourbood of faculæ are also fully given, the lines which appear to have been seen in nearly every eruption are $\mathrm{D}, b^{1} b^{2} b^{3} b^{4}, 4,943,5,03 \mathrm{I}$, and 5,316 ; the other lines less frequently seen are $5,263,5,272,5,282,5,226$, $5,232,5,234$, and 5,195 .

Oct. 1875.-Prof. Tacchini gives a note on his observations in the previous number, and remarks the greater number of eruptions of magnesium on the western limb than on the eastern ; the numbers on the former being more than double those on the eastern. The actual numbers for each month in 1873 are given. The number of eruptions in the northern and southern hemispheres are equal to each other. The zones of maximum erup: tions appear to be between $N$. lat. $10^{\circ}$ and $20^{\circ}$, and $S$. lat $0^{\circ}$ and $10^{\circ}$.-Communications from Father Secchi, Prof. Dorna, and Prof. Tacchini on the partial sular eclipse of Sept. 29, $1875^{\circ}$ It is remarkable that the first contact was observed by the spectroscopic method some seconds later than by the simple teiescopes, and the last contact several seconds earlier.-Drawings of the solar prominences during the months of May and June 1874 by Secchi and Tacchini accompany this number.

Zeitschrift der Oesterreichischen Gesellschaft für Metcorologie, Dec. I, 1875.-The concluding part of Herr Wild's paper on the late congresses appears in this number. Against what has been said of these gatherings, that their sole result would be the accumulation of millions of useless observations upon the millions that have already been published, he contends that in his opinion observations are useless only when they are faulty and inaccessible; and that he has found himself bampered, not by their great quantity, but by their deficiencies, inconvenience of form, or variety of arrangement. It is true that out of mil. lions of figures perhaps only some thousands prove of value to the investigator; but who can decide which will and which will not eventually be used? Registers intended for publication are submitted to a more careful revision than those preserved only 
in manuscript. Indeed, Dr. Wild would almost lay it down as a rule that unpublished observations should be deemed scientifically useless. As to congresses, he does not think that they should be occupied with discussions on the laws of meteorology. The derivation of laws from observations should be looked for in the undisturbed thoughifulness of individuals. Experience shows, however, that private persons do not employ themselves as much as formerly in working out observations, and it seems to be absolutely necessary for the advancement of meteorology that every official observer should be given sufficient time, beyond that required for mechanical work, for developing the science as far as his powers will permit, and that the central institutions should be adequately endowed for this purpose.--The next paper is a review, by Dr. Hann, of the publications of Messrs. Fjord and Paul la Cour on the climate of Denmark, which contain very valuable statistics in the decennial means of fourteen stations. As in other similarly situated countries, both the heat of summer and the cold of winter are more intense inland than on the coasts, and in July the most easterly stations are the warmest. The mild weather of spring seems to advance from S.W. to N.E., and the cool weather of October from N.W. to S.E. Thus the mean temperature of $8^{\circ}$ is reached in N.W. Jitland on the IIth, in Bornholm and the northern extremity of Rügen between the 23rd and 24th of October. The mean monthly range of temperature is greatest in May, least in January; from April to August the maxima rise higher above the monthly mean than the minima sink below it ; from September to March the relation is converse. The absolute maximum range was registered in July, the absolute minimum in November. The average number of days on which frost occurs is ninety-two; tirne of maximum rainfall the latter end of August and beginning of September ; of minimum, the beginning of April. Yearly mean rainfall-in Denmark, $604 \mathrm{~mm}$. ; on the west coast of Jitland, $670 \mathrm{~mm}$; ; at Copenhagen, $587 \mathrm{~mm}$. ; Bornholm, $580 \mathrm{~mm}$.. A small table inserted here by Dr. Hann gives a great deal of information as to days on which rain fell, and on which thunderstorms, hailstorms, fog, and cloud occurred. January is the cloudiest, May and July are the least cloudy of months. Tables showing the frequency per cent. of the different winds and the monthly barometric pressure close Dr. Hann's summary of the valuable work under review.- In the Kleinere Mittheilungen, Dr.Gustav Hellmann states the chief results of his incuiries into the distribution of thunderstorms in Northern Germany. In general the annual mean number of thunderstorms in Germany increases from N.E. to S.W. It is least on the coasts of the Baliic, particularly in East Prussia greatest in the district of the Upper Rhine. On the eastern coast of the Baltic about twelve are observed in the year; on the western coast of the Baltic, sixteen; and on the coast of the North Sea, fifteen. Inland, the number averages twenty. They increase in number with increasing altitude, up to about $1,400 \mathrm{~m}$., then decrease rapidly. Winter thunderstorms are much more common in Northern Germany than in Austria and Hungary.

\section{SOCIETIES AND ACADEMIES LONDON}

Royal Society, March 30.- "An Experiment on ElectroMagnetic Rotation." By W. Spottiswoode, M.A., Treas. and V.P.R.S.

The phenomena of the rotation of movable conductors, carrying currents, about lines of magnetic force, are well known. One form of experiment, commonly called the rotating spark, presents, beside the actual rotation, some peculiar features which do not appear to have been noticed in detail.

The spark, when carefully observed, is seen to assume a spiral form ; and the spiral is right-handed or left-handed according to both the direction of the current and the magnetic polarity. This effect is particularly noticeable if the magnetic pole be in serted only a short distance beyond the ring. The discharge is then seen to spread itself out sheetwise on the ring in the direction in which rotation would take place. The edge of the sheet is in the form of a belix.

The object of the following observations is to bring out the character of this phenomenon by making it a principal instead of a secondary feature of the experiment.

The arrangement here described consisted in using the poles of an electro-magnet as the terminals of a discharge from an induction-coil, and in observing the effect on the form of the discharge caused by exciting the electro-magnet." For this purpose the movable poles were insulated from the main body of the magnet by interposing a sheet of ebonite thick enough to prevent the passage of the discharge. The discharge was then effected either in the open air or in a closed chamber. The latter was constructed of a short cylinder of glass, say 3 inches in length and 2 in diameter, having conical ends pointed inwards, so as to receive the poles of the magnet. The chamber was also furnished with a pipe and stop-cock for the purposes of exhaustion.

The discharge from an induction-coil taken in air or other gas at atmospheric pressure, consists, as is well known, primarily of the spark proper or bright line, irregular in form and instantaneous in duration. But beside this, when the primary wire is thick and the kattery-current strong, the spark is enveloped in a bright cloud, or rather flame, which is capable of being thrown on one side, although not entirely detached from the spark by a current of air. This, when examined in a revolving mirror, is found to be subsequent in time to the spark proper, and may be considered to be due to the gas in the neighbourhood of the spark becoming sufficiently heated to conduct part of the discharge, and to the consequent combustion of any extraneous matter floating in the medium. Such a view is supported by the fact that the colour of this flame depends partly, upon the nature of the gas in which the discharge takes place, and partly upon that of any volatilisable matter which may be introduced near the poles.

The exciting of the magnet produces upon 'the: spark proper no appreciable effect ; but as soon as the flame is submitted to its action it is spread out into a sheet, which arranges itself in a helicoid right-handed or left-handed according to the direction of the current and of the magnetic polarity in obelience to Ampère's law.

Effects substantially the same are produced whether the discharge be taken in gas at atmospheric or at a less pressure. But in the former case the helix. has a lower, in the latter a steeper gradient; that is to say, in the former case it presents a greater, in the latter a less number of turns, for a given interval between the poles.

Various gases were tried-atmospheric air, carbonic acid, ether, chloroform, coal-gas, hydrogen. Of these the first two succeeded best. With air the illumination of the flame-sheet was rather greater; but with carbonic acid greater steadiness of position was cbtained. With both ether and chloroform, occasional flashes, brilliantly illuminated, were seen; but sonue chemical action appeared to take place militating asainst the steady development of the flame-sheet. With coal-yas there was an inconvenient deposit of carbon upon the sides of the chamber. With hydrogen the cloud was not sufficiently developed.

The success which attended the experiment with air may possibly be partly due, as suggested above, to the combustion of the extraneous matter floating therein; and in fact the brilliancy and extent of the sheet may be increased by attaching a piece of metallic sodium to the negative terminal, or by causing a stream of any of the chlorides in powder, e.s., of strontium, lithium, \&c., to flow across the field of action.

When a piece of sodium (or better still of soda) is attached to one of the terminals, two effects may be noticed. When that terminal is negative the whole of the flame is bright yellow, showing that the sodium is not only detached but even carried across the field and deposited on the positive terminal. When, however, the terminal, to which the sodium is attached is positive, it is found that the flame, when observed through a recl glass, appears yellow to a certain distance from the (positive) terminal to which the sodium is attached, but red beyond; an: also that the pitch of the helix is less near the position than near the negative terminal. These effects may be attributed to the presence of metallic vapour evolved by the heat at the positive terminal, but not carried across the field as when the terminal in question is negative.

The following explanation of the phenomenon, from which the mathematical part is omitted, is due to Prof. Stokes. Supposing the magnetic field to be uniform, the lines of force will be straight lines from pole to pole. In such a condition every. thing being symmetrical no rotation would take place. But if through any local circumstance the path of the current be distorted and displaced, then each element will be subject to two forces, one tending to turn the current round the axis, the other tending to make it follow the shortest path so as to diminish the resistance.

And the general nature of the phenomenon may be described as follows:- "First, we have the bright spark of no sensible 